\title{
A Descriptive Comparison Of Two Sources Of Occupational Fraud Data
}

\author{
George L. Hunt, Stephen F. Austin State University, USA
}

\begin{abstract}
The propose of this study was to determine if the data contained in the Internal Auditor "Roundtable" and "Fraud Finding" columns are consistent with data reported in the ACFE's Report to the Nation. Cases of fraud reported in the Internal Auditor columns were analyzed, summarized, and compared to the data contained in the Report to the Nation. The results show significant similarities between the two data sources.
\end{abstract}

Keywords: Fraud; Fraud Data; Occurrence of Fraud; Data Mining; Internal Auditing; Fraud Examiner

\section{INTRODUCTION}

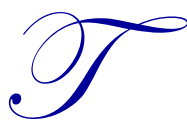

he Association of Certified Fraud Examiners (ACFE) first began surveying members about their fraud investigations in 1996. The survey results were published in the inaugural Report to the Nation on Occupational Fraud and Abuse. Since 2002, the ACFE has reported results of a bi-annual survey; the results of which are useful in understanding what frauds are occurring and how to stop them. Another source of data that may also be useful, but has not previously been analyzed, is the Internal Auditor magazine where fraud cases have been reported.

This study attempts to determine if the submissions to the Internal Auditor columns are consistent with the results of the ACFE's Report to the Nation. Cases of fraud reported in the Internal Auditor columns were analyzed, summarized, and compared to the data contained in the Report to the Nation. If the Internal Auditor data is consistent with the ACFE data, the columns can provide a valid historical perspective in the fight against fraud. The balance of this paper discusses characteristics of the two data sources, the method of capturing and analyzing the data, and the results of the comparison.

\section{The Two Sources of Data on Occupational Fraud}

Some of the most comprehensive and ongoing research into occupational fraud is conducted by the Association of Certified Fraud Examiners. Another potential source of information is the Internal Auditor's "Roundtable" and "Fraud Findings" columns. Characteristics of each source of information are discussed below.

The Report to the Nation on Occupational Fraud and Abuse

The Association of Certified Fraud Examiners periodically surveys its 50,000+ members about the most significant fraud investigation in which they have participated during the preceding two-year period. The surveys are extensive, typically contain 70 questions or more, and often require respondent-prepared narratives (for example, see ACFE, 2006).

The results are published in a series of monographs titled Report to the Nation on Occupational Fraud and Abuse (hereafter referred to as the Report or Reports). The initial Report was published in 1996 and since 2002, the ACFE has published a bi-annual report on the results of these surveys.

Over the years, the information collected by the ACFE has evolved as enhancements were made to the survey instrument, but certain key information has remained consistent since the 2002 Report. The type of fraud 
committed, dollar losses incurred by victim organizations, certain characteristics of the perpetrators and victim organizations, resolution of cases, and demographic information are some of the items consistently reported.

Because of this consistency in reporting of certain key elements, results from the 2002 through 2012 Reports were used for comparison purposes. There were a total of 6,495 cases reported in that time period, providing a sizable data set to use as a benchmark for comparison.

One item to note is the level of detail provided by the ACFE research, which allowed identification and reporting of multiple types of fraud occurring simultaneously (e.g. skimming both cash and receivables). There were 380 cases $(33.5 \%)$ of multiple frauds contained in the Reports. By contrast, only eight cases $(2.0 \%)$ could be identified as having multiple types of fraud occurring simultaneously from the vignettes provided in the Internal Auditor. "Double counting" these multiple simultaneous frauds in the Reports results in the frequencies reported adding to more than $100 \%$.

A second consideration is the change in the 2010 and 2012 Reports from a U.S.-based survey only to one that includes all nations. This study used the raw data from both Reports because the Internal Auditor column also included some foreign submissions.

\section{The 'Internal Auditor' Columns}

This study is not the first to use of the vignettes in the Internal Auditor columns for research. For example, in 1989 Theresa Park presented a summary of information gathered from 51 fraud cases recounted in the "Roundtable" column. Three years later (June 1992), Raymond Jeffords and others presented an analysis of the usefulness of the Treadway Commission's risk factors based on 910 cases reported in the columns.

In this study, twenty-five years of the Internal Auditor "Roundtable" and "Fraud Findings" columns were reviewed to identify cases of fraud. During the period January 1980 through December 2005, there were 1,712 narratives reported in the "Roundtable" column and 142 cases of fraud reported in the "Fraud Findings" column (which was first published in March 1990).

The Internal Auditor's "Roundtable" vignettes are generally brief, with an average word count of approximately 150 words (287 of the 403 usable vignettes came from the "Roundtable" column). The "Fraud Findings" column provided a bit more detail about the frauds, averaging about 1,600 words per vignette (116 of the useable vignettes were from the "Fraud Findings" columns). The lack of detail in the Internal Auditor vignettes limited the number of comparisons with the ACFE data.

A total of 403 vignettes involved fraud and provided enough detail to classify the fraud under the Uniform Occupational Fraud Classifications System (also known as the "fraud tree"). They were further analyzed to determine:

- $\quad$ The relative frequency of cash and non-cash cases within the asset misappropriations category

- $\quad$ How frequently frauds were perpetrated by (1) employees, (2) managers, and (3) owners/executives

- How often collusion occurred

- The frequency that males committed fraud versus females

- The dollar losses incurred

- $\quad$ How the fraud was detected

\section{DATA COLLECTION}

The Reports are based on detailed information about the fraud cases included in the ACFE research. The statistics published in the Reports are used as originally reported, with one exception. The statistics rendered in the reports were weighted and averaged over the periods examined, resulting in a point estimate for the combined six biannual Reports. To provide a measure of the variability of the Report values over the years, the ranges of values from the 2002 through 2012 Reports are also presented. 
The vignettes were examined by graduate and undergraduate accounting students from an accredited state university. Students were randomly assigned a group of vignettes and asked to classify the fraud according to the ACFE fraud tree to the most detailed level possible. They were also given a template with which to collect other items of interest. Each vignette was examined by multiple examiners, with the minimum review by three students and the lead researcher. The agreement rate for the examiners was $97.4 \%$. The values gathered by the analyses were averaged over all usable cases, except dollar loses. Losses are reported at median values (rather than averages) to remain consistent with the Reports.

As discussed above, the bi-annual Reports are based on detailed information about the frauds while submissions to the Internal Auditor were often brief and lacked sufficient detail to capture all the characteristics presented in the Reports. Nevertheless, where possible, each item contained in the Reports was collected from the Internal Auditor cases.

\section{RESULTS}

Notwithstanding the differences in the two data sources, the comparison of the sources proves interesting and informative. The following section outlines the comparison by frequency of occurrence, dollar loss ratios, and the effects of gender and number of perpetrators on the frequency of occurrence. Methods of detection are also compared.

\section{Frequency by Fraud Method}

When the cases are classified under the Uniform Occupational Fraud Classifications System (fraud tree), it is clear how similar the two sources are in terms of frequencies in each category. As Table 1 shows, asset misappropriation accounted for $88.1 \%$ of the frauds included in the Reports compared to $87.3 \%$ of the Internal Auditor cases. Asset misappropriation is the most common method of fraud in each source by a large margin with corruption and fraudulent statements distant second and third in terms of frequency of occurrence.

Table 1: Frequency by Fraud Method

\begin{tabular}{|l|c|c|c|}
\hline & Internal Auditor & ACFE Reports & ACFE Range \\
\hline Asset Misappropriation & $87.3 \%$ & $88.1 \%$ & $85.7 \%-92.7 \%$ \\
\hline Corruption & $12.2 \%$ & $29.5 \%$ & $12.8 \%-33.4 \%$ \\
\hline Fraudulent Statements & $7.7 \%$ & $7.5 \%$ & $5.1 \%-10.6 \%$ \\
\hline
\end{tabular}

When asset misappropriation cases are further broken down into cash (e.g., currency, checks, receivables) and non-cash (e.g., inventories, equipment) categories as shown in Table 2, the relative frequencies again are very similar. Table 2 shows that $91.7 \%$ of the Internal Auditor cases were cash misappropriation and $93.7 \%$ of the Reports were cash misappropriation. Also shown in Tables 1 and 2 (and all subsequent tables) is the range of values reported by the ACFE research for the periods 2002 through 2012.

Table 2: Asset Misappropriations - Cash vs. Non-Cash

\begin{tabular}{|l|c|c|c|}
\hline & Internal Auditor & ACFE Reports & ACFE Range \\
\hline Cash & $91.7 \%$ & $93.7 \%$ & $87.7 \%-100.0 \%$ \\
\hline Non-cash & $8.3 \%$ & $17.6 \%$ & $10.6 \%-23.4 \%$ \\
\hline
\end{tabular}

\section{Dollar Losses by Fraud Method}

The Reports present median dollar losses to organizations based on various criteria, such as by size and type of organization and type of fraud. Also reported are median dollar losses by gender, position, number of perpetrators, and several other categories. Because the Internal Auditor narratives were generally brief, only certain categories of losses could be determined. These include median dollar losses by fraud method, perpetrator's position in the organization, and gender of the perpetrator. 
Table 3 reports the relative median dollar losses by fraud method. For both sources, the median losses for asset misappropriations are less than the median losses for corruption and fraudulent statements. However, comparisons should be viewed with skepticism because there were very few cases of corruption (20) and fraudulent statements (17) reported in the Internal Auditor.

Table 3: Median Loss by Fraud Method

\begin{tabular}{|l|c|c|c|}
\hline & Internal Auditor & ACFE Reports & ACFE Range \\
\hline Asset Misappropriation & $\$ 46,000$ & $\$ 121,333$ & $\$ 80,000-\$ 150,000$ \\
\hline Corruption & $\$ 625,000$ & $\$ 365,500$ & $\$ 250,000-\$ 538,000$ \\
\hline Fraudulent Statements & $\$ 440,000$ & $\$ 2,391,667$ & $\$ 1 \mathrm{M}-\$ 4.25 \mathrm{M}$ \\
\hline
\end{tabular}

Table 4 displays median dollar losses for cash asset misappropriations and non-cash asset misappropriations. The amount of loses suffered again are similar, with cash asset misappropriations being less than non-cash asset misappropriations in both sources. Again, there were few cases of non-cash asset misappropriations (11) reported in the Internal Auditor, so comparison with the Reports may be unreliable. However, the ranking of dollar losses is consistent between the two sources.

Table 4: Median Losses - Cash vs. Non-Cash

\begin{tabular}{|l|c|c|c|}
\hline & Internal Auditor & ACFE Reports & ACFE Range \\
\hline Cash & $\$ 46,000$ & $\$ 92,794$ & $\$ 76,000-\$ 150,000$ \\
\hline Non-Cash & $\$ 221,000$ & $\$ 124,667$ & $\$ 58,000-\$ 200,000$ \\
\hline
\end{tabular}

In summary, both sources tell the same story: asset misappropriations (and cash misappropriations within the category) are the most frequent frauds committed, but were the least costly to the victim organizations.

\section{Frequency and Dollar Losses by Perpetrator Characteristics}

Although the Reports contain many analyses by characteristics of the perpetrator (e.g. frequency and dollar losses of fraud by sex, age, tenure), the brevity of the Internal Auditor data limited comparison to only a few of the analyses contained in the Reports - the effect of gender and position on frequency of fraud and dollar losses, and whether the fraud was committed by a single perpetrator or in concert with others.

Table 5 summarizes the effect of gender on frequencies of fraud. Males perpetrated $61.8 \%$ of the frauds contained in the Reports while $74.3 \%$ of the fraudsters reported in the Internal Auditor were male (gender could be determined in 175 of the 403 Internal Auditor cases).

Table 5: Frequency by Gender

\begin{tabular}{|l|c|c|c|}
\hline & Internal Auditor & ACFE Reports & ACFE Range \\
\hline Male & $74.3 \%$ & $61.8 \%$ & $52.9 \%-66.7 \%$ \\
\hline Female & $25.7 \%$ & $38.2 \%$ & $33.3 \%-47.1 \%$ \\
\hline
\end{tabular}

Table 6 shows the effect of gender on median dollar losses. In both data sources, frauds committed by males were over two and a half times as costly as those committed by females.

Table 6: Median Loss by Gender

\begin{tabular}{|l|c|c|c|}
\hline & Internal Auditor & ACFE Reports & ACFE Range \\
\hline Male & $\$ 100,000$ & $\$ 215,333$ & $\$ 160,000-\$ 250,000$ \\
\hline Female & $\$ 32,500$ & $\$ 87,167$ & $\$ 60,000-\$ 110,000$ \\
\hline
\end{tabular}

Results from the Reports clearly show that a perpetrator's position with the organization affects both the frequencies and dollar impact of frauds. Most of the Internal Auditor cases (373 of 403 cases) indicated the perpetrator's position. Both data sources are consistent, indicating employees are more like to commit fraud than are managers or owner/executives, and managers are more likely than owner/executives to commit fraud. Table 7 summarizes the frequency of fraud by employment position. 
Table 7: Frequency by Position

\begin{tabular}{|l|c|c|c|}
\hline & Internal Auditor & ACFE Reports & ACFE Range \\
\hline Employee & $62.2 \%$ & $45.7 \%$ & $39.5 \%-67.8 \%$ \\
\hline Manager & $32.4 \%$ & $39.0 \%$ & $34.0 \%-41.9 \%$ \\
\hline Owner & $5.4 \%$ & $18.2 \%$ & $12.4 \%-23.3 \%$ \\
\hline
\end{tabular}

Table 8 reports the median losses by perpetrator's position with the organization. In both data sources, dollar losses increase as the perpetrator's level of authority increases. The median dollar losses for managers are approximately three to four times the amount of losses suffered at the hands of employees and median dollar losses for owners/executives are four to five times as great as frauds committed by managers.

Table 8: Median Loss by Position

\begin{tabular}{|l|c|c|c|}
\hline & Internal Auditor & ACFE Reports & ACFE Range \\
\hline Employee & $\$ 27,000$ & $\$ 70,000$ & $\$ 60,000-\$ 80,000$ \\
\hline Manager & $\$ 100,000$ & $\$ 190,000$ & $\$ 140,000-\$ 250,000$ \\
\hline Owner & $\$ 450,000$ & $\$ 806,000$ & $\$ 573,000-\$ 1 \mathrm{M}$ \\
\hline
\end{tabular}

The frequency of frauds committed by a single perpetrator and those involving more than one perpetrator are reported in Table 9. The Reports found 39.5\% of their cases involved collusion, while $24.2 \%$ of the cases of fraud reported in the Internal Auditor involved collusion (397 of the 403 cases provided enough information to determine whether collusion occurred). In both sources, the majority of the cases were committed by a single individual.

Table 9: Frequency by Number of Perpetrators

\begin{tabular}{|l|c|c|c|}
\hline & Internal Auditor & ACFE Report & ACFE Range \\
\hline Solo & $75.8 \%$ & $60.5 \%$ & $57.0 \%-67.6 \%$ \\
\hline Collusion & $24.2 \%$ & $39.5 \%$ & $32.4 \%-43.0 \%$ \\
\hline
\end{tabular}

The relative dollar losses associated with the number of perpetrators are consistent between the two data sources. As shown in Table 10, in both the Internal Auditor and the Reports collusion resulted in losses of almost five times those committed by a single perpetrator.

Table 10: Dollar Losses by Number of Perpetrators

\begin{tabular}{|l|c|c|c|}
\hline & Internal Auditor & ACFE Reports & ACFE Range \\
\hline Solo & $\$ 40,000$ & $\$ 90,083$ & $\$ 58,500-\$ 115,000$ \\
\hline Collusion & $\$ 190,000$ & $\$ 375,167$ & $\$ 200,000-\$ 500,000$ \\
\hline
\end{tabular}

\section{Method of Detection}

Ninety percent of the cases reported in the Internal Auditor indicated how the fraud was initially detected. The Reports found that internal audits were responsible for discovering $17.2 \%$ of fraud cases, while $63.8 \%$ of the Internal Auditor fraud cases were detected through internal audit activities. Internal controls were responsible for detecting $5.2 \%$ of frauds reported in the Internal Auditor with $24.0 \%$ being detected by internal controls in the Reports data.

The most frequent method of initial discovery of fraud in the Reports data was from tips (e.g., employees, customers, vendors, anonymous sources). In the Internal Auditor, only $18.9 \%$ of the frauds were discovered by tips, while tips accounted for $40.7 \%$ in the Reports. Third in both sources was discovery by accident $(11.2 \%$ in the Internal Auditor and $14.8 \%$ in the Reports). Table 11 summarizes fraud discovery by source. 
Table 11: Frequency of Detection by Source

\begin{tabular}{|l|c|c|c|}
\hline & Internal Auditor & ACFE Report & ACFE Range \\
\hline Internal Audit & $63.8 \%$ & $17.2 \%$ & $13.9 \%-23.8 \%$ \\
\hline Tip & $18.9 \%$ & $40.7 \%$ & $34.2 \%-46.2 \%$ \\
\hline By Accident & $11.2 \%$ & $14.8 \%$ & $7.0 \%-25.4 \%$ \\
\hline Internal Controls & $5.2 \%$ & $24.0 \%$ & $15.4 \%-30.1 \%$ \\
\hline External Audit & $0.8 \%$ & $7.5 \%$ & $3.3 \%-12.0 \%$ \\
\hline Notified by Law Enforcement & $1.4 \%$ & $2.5 \%$ & $0.9 \%-3.8 \%$ \\
\hline
\end{tabular}

\section{CONCLUSION}

This paper compared a compilation of fraud cases reported in the "Roundtable" and "Fraud Findings" columns in Internal Auditor with a summary of the Report to the Nation on Fraud and Abuse published by the Association of Certified Fraud Examiners over the period 2002 - 2012.

The comparison provides evidence that the "Roundtable" and "Fraud Findings" columns in Internal Auditor have been a valuable resource for its readers. Frequencies of occurrence and median dollar losses by fraud method are generally consistent in both the Internal Auditor and the Reports. Frequencies of occurrence and median dollar losses categorized by perpetrator characteristic (e.g., job position, gender, number of perpetrators) are also consistent between sources.

Although the data analyzed in this study were collected from fundamentally different sources and covered different time periods, the comparison highlights the consistency of the data between the two data sources. While additional empirical analyses could support more robust conclusions, this initial study provides some assurance that the use of the Internal Auditor columns may be useful in the detection of fraud.

\section{AUTHOR INFORMATION}

George L. Hunt, CPA, CIA, CFE, is an associate professor of accounting with the Gerald W. Schlief School of Accountancy at Stephen F. Austin State University. He is a member of the Association of Certified Fraud Examiners and the Institute of Internal Auditors. He has written articles for the Internal Auditor, Journal of Business and Economics, and Today's CPA. E-mail: huntgl@sfasu.edu

\section{REFERENCES}

1. Association of Certified Fraud Examiners (2002 - 2012). Report to the Nation on Occupational Fraud and Abuse. ACFE, $2002-2012$.

2. Association of Certified Fraud Examiners (2006). National Fraud Survey. ACFE, Jan. 31, 2006.

3. Jeffords, Jr., R., Merchant, M. L., \& Bridendall, P. H. (1989). How Useful are the treadway risk factors? Internal Auditor, June 1992, 60-61.

4. Park, T. (1989). Business fraud as reported by internal auditors in the Internal Auditor. Internal Auditor, June 1989, 67-69. 